\title{
Variability of the obturator artery with its surgical implications
}

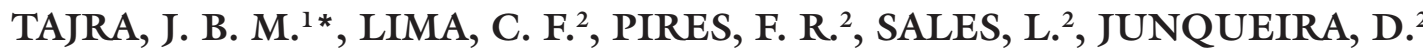 \\ and MAURO, E. ${ }^{2}$ \\ ${ }^{1}$ Departamento de Anatomia, Faculdade de Medicina do Planalto Central, CEP 71215-770, Brasília, DF, Brazil \\ ${ }^{2}$ Anatomia Médica, Faculdade de Medicina do Planalto Central, CEP 71215-770, Brasília, DF, Brazil \\ *E-mail: jbtajra@uol.com.br
}

\begin{abstract}
The vascular anatomy of the pelvis has in the retro pubic space one the most dangerous artery variations for the surgical approach. The aim of this study was to evaluate arise from obturator artery and its implications. Eleven specimens were bisected pelvic an adult cadaver. The iliac artery and femoral artery were identified and divided in their branches. The anomalous origin was noted in $22.72 \%$ with an anastomotic branch between the external iliac or inferior epigastric vessels found in $13.69 \%$. The right side showed a greater variation than left side with $27.27 \%$ versus $18.18 \%$. Our data suggest that retro pubic space has critical vascular variations of the obturator artery with many probabilities of the lesions.
\end{abstract}

Keywords: vascular anatomy, obturador artery, pelvis anatomy.

\section{Introduction}

The retro pubic space has a vascular anatomy that must be known to the surgeon to avoid hemorrhagic complications. In this region, the anomalous origin of obturator artery (OA) and its variations are the main etiology of bleeding (CONDON and NYHUS, 1991). The OA is one of the branches of the anterior division of the internal iliac artery, inclines antero-inferiorly on the lateral pelvic cavity by passing through the obturator foramen (GRAY, 1901). On each side, the anterior division gives rise to the superior vesical artery, inferior vesical artery, middle rectal artery, vaginal artery, obturator artery, inferior gluteal artery and internal pudendal artery (JUSOH, ABD RAHMAN, ABD LATIFF et al., 2010). The various origins of the OA observed for Sañudo, Mirapeix, Niedenführ et al. (2011) revealed a single origin in $96.55 \%$. The OA arising from inferior epigastric artery (EA) has gone chief variation got after posterior trunk of internal iliac artery (IIA) (SAÑUDO, MIRAPEIX, NIEDENFÜHR et al., 2011). The most dangerous variation has origin from presence of the dual origin of the OA arising both IIA and external iliac artery, anastomoses between them is known as corona mortis or crown of death, because of the profuse bleeding that can occur when either of the vessels is severed (SUMATHILATHA, SHARMILA, SAKTHIVELAVAN et al., 2013). The procedures that are performed in this area involve repairs for femoral and inguinal hernias, fracture of pubic ramus and urogynecological surgeries. The objective of this study was to demonstrate the main variations of the obturator artery performed by dissecting 24 pelvic half of the adult cadavers in anatomy laboratory of Faciplac-Brazil and their applications in surgical practice.

\section{Materials and Methods}

The study was conducted using eleven specimens of the unique institution. Each specimen was a bisected pelvic half of an embalmed adult cadaver. The dissection was done by preclinical medical students manage by instructor. The specimens were obtained from 8 males and 4 females adult cadavers.
The vascular anatomy of the pelvis was dissected together with all the anatomical structures.

The internal iliac artery was identified and divided in yours trunks anterior and posterior. The course of the OA was followed until it enters in the obturator foramen. The external iliac artery and inferior epigastric artery were also exposed as well as the femoral ring and retro inguinal space. After each dissection was made a photographic record.

\section{Results}

The origins of the OA observed in the study was from internal iliac artery in $77.27 \%$ of specimens. The anomalous origin was noted in $22.72 \%$. OA was found arise from external iliac artery in $9.09 \%$ (Figure 1) and from inferior epigastric artery in $13.63 \%$ (Figure 2 ).

Among the 24 half pelvic studied $72.72 \%$ had similar origins of $\mathrm{OA}$ on both sides. The right side showed a greater variation than left side with $27.27 \%$ versus $18.18 \%$. All the anomalous origins had path across retro inguinal space and the superior pubic ramus. All origins of the OA in this study are summarized in Table 1.

\section{Discussion}

The most common source of the obturator artery origin is as a single branch arising from the anterior division of the internal iliac artery (EVANS and MCSHANE, 1985). However, many articles report variable origins. An unusual origin has attracted the attention of anatomist and surgeons overdue severe and potentially lethal complication bleeding involving retro inguinal space procedures (PAI, KRISHNAMURTHY, PRABHU et al., 2009). In any cases of vessel coursing over the superior pubic branch offers a surgical problem for orthopedic and general surgeons. When either of the vessels is injured the patient bleeds profusely from both the ends with considerable technical difficult to ligate them. This complication may lead 
Table 1. Types of origins the obturator artery in this study: IIA-Internal iliac artery.

\begin{tabular}{ccc}
\hline Type & Origin & Our study \% \\
\hline a & Anterior trunk IIA & 59.09 \\
b & Inf.epigastric artery & 13.63 \\
c & Posterior trunk IIA & 18.18 \\
d & IIA above division & 0 \\
e & External iliac artery & 9.09 \\
f & Femoral artery & 0 \\
\hline
\end{tabular}

to extra peritoneal hemorrhage and death (SARIKCIOGLU, SINDEL, AKYILDIZ et al., 2011).

In the present study, the origin of OA from internal iliac system was found in $77.27 \%$. Some authors demonstrated similar data as Roberts and Krishingner (1967), Biswas, Bandopadhyay, Adhikari et al. (2010) and Sañudo, Mirapeix, Niedenführ et al. (2011). The anterior division was found in $59.09 \%$ and posterior division in $18,18 \%$. This is a usual position of this artery. It's passes forward and downward on the lateral wall of the pelvis, to the upper part of the obturator foramen and escaping from the pelvic cavity through the obturator canal (GRAY, 1901).

Nevertheless the OA origin from the external iliac system was $22.72 \%$ (including the dual origin) with found to originate as direct branch of the external iliac artery in $9.09 \%$. This is higher than the findings of oldies studies of 1.1-1.3\% (BRAITWAITE, 1952; ROBERTS and KRISHINGNER, 1967) but similar than the finding of Mahato (2009), who noted such an origin in $10 \%$. The OA arising from the external iliac system has a clinical advantage. In cases of obstruction of the internal iliac artery due to any cause, there will be sparing of OA and its branches especially the head od femur artery.

The origin of OA from the inferior epigastric artery in our study was found in $13.63 \%$. In some studies were observed this source in 14 to $33 \%$. (PAI, KRISHNAMURTHY, PRABHU et al., 2009). During normal development, the inferior epigastric artery is established at an earlier stage than OA as a channel for blood supply. This fact is one the reasons why the epigastric artery from OA is very rare in comparison to the OA from the inferior epigastric artery (PAI, KRISHNAMURTHY, PRABHU et al., 2009). The close proximity of this abnormal OA to the pubis and the lacunar ligament at the medial edge of the femoral canal poses important considerations in several contexts. Fracture of the branch pubic bone, release of the lacunar ligament during reduction and repair of femoral hernias, laparoscopic repair of inguinal hernias, surgical management of acetabular fractures and gynecological procedures are where care must be regards by inadvertent injury (MAHATO, 2009).

The "corona mortis" is an anatomical variant with an anastomosis between external iliac system and internal iliac system located on the superior pubic ramus. In this case OA has a dual origin. This anomaly is especially danger for orthopedic surgeon in the pelvic trauma and laparoscopy repair of inguinal hernia. Despite this anomaly, surgeons should exercise caution in the operating room. Rusu, Cergan, Motoc et al. (2010) has been proposed any vessel coursing over the superior pubic branch would be termed "corona mortis" (Figures 2 and 3 ). The present study has this situation in $13.69 \%$.

Hypogastric artery ligation does have a specific role in the management of pelvic surgeries, but it is not without

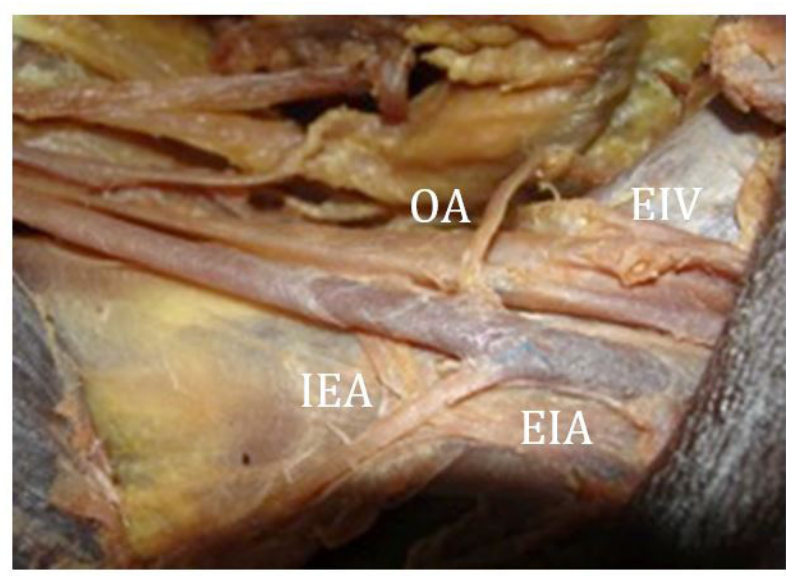

Figure 1. Half pelvic showing the origin of OA from external iliac artery. OA - obturatory artery; EIA - external iliac artery; IEA - inferior epigastric artery; EIV - external iliac vein.

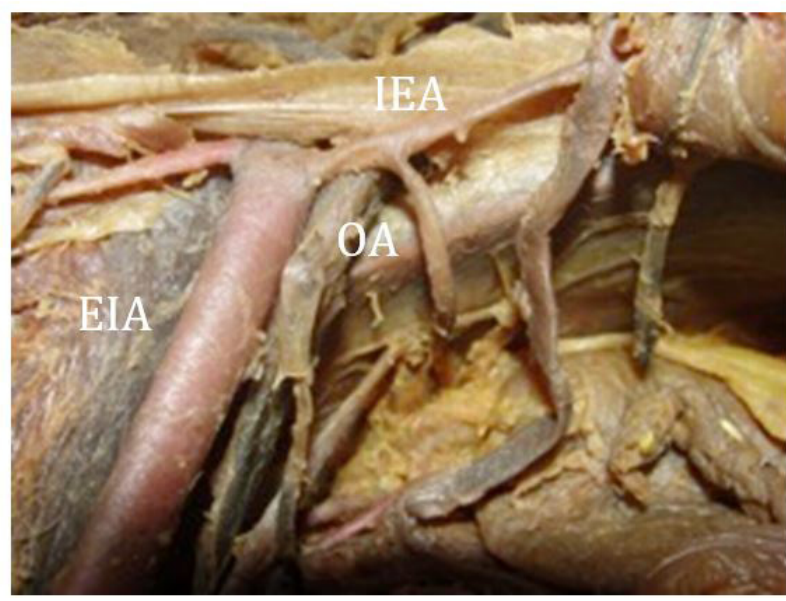

Figure 2. Overview of Half pelvic showing the anomalous origin of obturatory artery arising from inferior epigastric artery. OA - obturatory artery; EIA - external iliac artery; IEA - inferior epigastric artery.

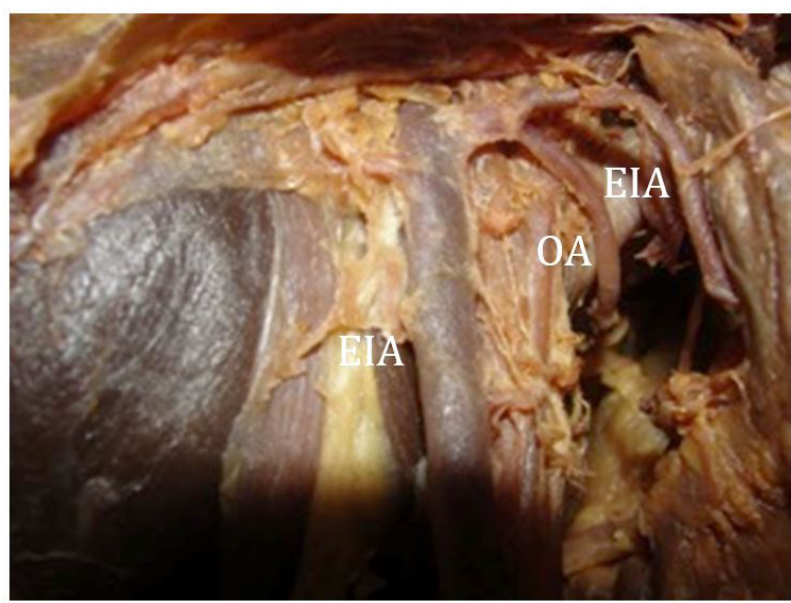

Figure 3. Half pelvic showing the dual origin from external iliac artery (EIA): inferior epigastric artery (IEA) and Obturatory artery (OA). 
substantial risk of failure (EVANS and MCSHANE, 1985). Recent reports depict that the efficacy of the internal iliac artery ligation during any obstetrics and gynecology surgery may vary between $42-75 \%$ (SZILLER, HUPUCZI and PAPP, 2007). Ideally, one would ligate the internal iliac artery to its posterior division because proximal ligation has been associated with buttock claudication and necrosis (SZILLER, HUPUCZI and PAPP, 2007).

\section{Conclusions}

The data obtained in this study show that retro pubic space has a critical vascular anatomy. In this region, the obturator artery has been ranged in $22.72 \%$ with many probability of the lesion.

Acknowledgements: The authors wish to thank to Anatomy Laboratory- Faciplac and unknown bodies donated.

Conflict of interest: The authors declare that they have no conflict of interest

\section{References}

BISWAS, S., BANDOPADHYAY, M., ADHIKARI, A., KUNDU, P. and ROY, R. Variation of origin of obturator artery in Eastern India population: a study. Journal of the Anatomical Society of India, 2010, vol. 59, n. 2, p. 168-172. http://dx.doi.org/10.1016/S00032778(10)80019-X.

BRAITWAITE, JL. Variations in origin of the parietal branches of the internal iliac artery. Journal of Anatomy, 1952, vol. 86, n. 4, p. 423-430. PMid:12999644.

CONDON, RE. and NYHUS, LM. Complicaciones de la hérnia inguinal. 3rd ed. In NYHUS, LM. and CONDON, RE. (Eds). Hernia. 3rd ed. Philadelphia: Lippincott, 1991.

EVANS, S. and MCSHANE, P. The efficacy of internal iliac artery ligation in obstetric hemorrhage. Surgery, Gynecology \& Obstetrics, 1985, vol. 160, n. 3, p. 250-253. PMid:3871975.

GRAY, H. Anatomy descriptive and surgical. Pennsylvania: Courage Books, 1901.
JUSOH, AR., ABD RAHMAN, N., ABD LATIFF, A., OTHMAN, F., DAS, S., ABD GHAFAR, N., HAJI SUHAIMI, F., HUSSAN, F. and MAATOQ SULAIMAN, I. The anomalous origin and branches of the obturator artery with its clinical implications. Romanian Journal of Morphology and Embryology, 2010, vol. 51, n. 1, p. 163166. PMid:20191138.

MAHATO, NK. Retro-pubic vascular anomalies: a study of abnormal obturator vessels. European Journal of Anatomy, 2009, vol. 13, n. 3, p. 121-126.

PAI, MM., KRISHNAMURTHY, A., PRABHU, LV., PAI, MV., KUMAR, SA. and HADIMANI, GA. Variability in the origin of the obturator artery. Clinics, 2009, vol. 64, n. 9, p. 897-901. http:// dx.doi.org/10.1590/S1807-59322009000900011. PMid:19759884.

ROBERTS, WH. and KRISHINGNER, GL. Comparative study of human internal iliac artery based on Adachi classification. The Anatomical Record, 1967, vol. 158, n. 2, p. 191-196. http://dx.doi. org/10.1002/ar.1091580208. PMid:6034641.

RUSU, MC., CERGAN, R., MOTOC, AG., FOLESCU, R. and POP, E. Anatomical considerations on the corona mortis. Surgical and Radiologic Anatomy, 2010, vol. 32, n. 1, p. 17-24. http://dx.doi. org/10.1007/s00276-009-0534-7. PMid:19636491.

SAÑUDO, JR., MIRAPEIX, R., NIEDENFÜHR, MR., MARANILLO, E., PARKIN, IG. and VÁZQUEZ, T. Obturador artery revisited. International Urogynecology Journal and Pelvic Floor Dysfunction, 2011, vol. 22, n. 10, p. 1313-1318. http://dx.doi.org/10.1007/ s00192-011-1467-3.

SARIKCIOGLU, L., SINDEL, M., AKYILDIZ, F. and GUR, S. Anastomotic vessels in the retro pubic region: Corona mortis. Folia Morphologica, 2011, vol. 62, p. 179-182. PMid:14507043.

SUMATHILATHA, S., SHARMILA, A., SAKTHIVELAVAN, DS. and JEBAKKANI, CF. Variability of the obturator artery and its surgical implications in a South Indian population. European Journal of Anatomy, 2013, vol. 17, n. 3, p. 159-165.

SZILLER, I., HUPUCZI, P. and PAPP, Z. Hypogastric artery ligation for severe hemorrhage in obstetric patients. Journal of Perinatal Medicine, 2007, vol. 35, n. 3, p. 187-192. http://dx.doi. org/10.1515/JPM.2007.049. PMid:17480145.

Received June 26, 2015 Accepted July 9, 2016 